\title{
Molecular Epidemiology of Methicillin Resistant Staphylococcus aureus Isolated from Newborns in a Hospital in Rio de Janeiro, Brazil
}

\author{
MM Loureiro, BA de Moraes, MRR Quadra**, GS Pinheiro**, PN Suffys*, \\ MD Asensi ${ }^{+}$
}

\begin{abstract}
Laboratório de Enterobactérias, Departamento de Bacteriologia *Laboratório de Biologia Molecular e Diagnóstico de Doenças Infecciosas, Departamento de Bioquímica e Biologia Molecular, Instituto Oswaldo Cruz, Av. Brasil 4365, 21045-900, Rio de Janeiro, RJ, Brasil **Hospital Maternidade Alexander Fleming II, Sistema Único de Saúde, Rio de Janeiro, RJ, Brasil
\end{abstract}

\begin{abstract}
Methicillin resistant Staphylococcus aureus (MRSA) is an organism that is frequently transmitted in hospitals and perinatal units. The MRSA is considered a public health problem in neonatology because of its strong potential for dissemination in the wards associated with high rates of morbidity and mortality. In this study we describe the bacteriological, epidemiological and molecular characteristics of MRSA isolated from anterior nares and blood cultures of newborns hospitalized in a public maternity hospital in the city of Rio de Janeiro, Brazil. The frequency of MRSA isolated from nasal swabs of newborns was $47.8 \%$ (43/90). The genetic analysis of MRSA strains from anterior nares, showed 8 different pulsed field gel electrophoresis patterns (PFGE). Upon analysis of PFGE patterns of the 12 MRSA strains isolated from blood cultures, 8 different patterns were observed, $9(75 \%)$ strains were genetic related to nasal secretion isolates patterns. In conclusion, our data demonstrate the importance of screening of newborns for the presence of MRSA in Brazilian hospitals and the usefulness of genetic typing of these pathogen during epidemiologic studies. This should lead to a better knowledge on the significancy and spreading of MRSA in the hospitals.
\end{abstract}

Key words: newborns - nasal carriers - methicillin resistant Staphylococcus aureus - blood culture pulsed field gel electrophoresis - hospital infection - Rio de Janeiro - Brazil

The newborns in intensive and/or intermediate care units are considerably susceptible to acquire hospital infections of several microrganisms (Pujol et al. 1994, Haley et al. 1995). Methicillin resistant Staphylococcus aureus (MRSA) has emerged over the past 30 years as an important cause of hospital infections and is actually an organism that is frequently transmitted in hospitals and perinatal units (Haley et al. 1982, Boyce et al. 1994, Na'Was et al. 1998). Outbreaks causing several pathological problems to the newborns and mothers have been reported (Pujol et al. 1996, Corbella et al. 1997). The MRSA is considered a public health problem in neonatology because of its strong po-

Financial support: CNPq and Papes (Fiocruz)

The authors dedicate this paper in honor of the Oswaldo Cruz Institute, on the occasion of the centenary of its foundation, May 25th 1900.

${ }^{+}$Corresponding author. Fax: + 55-21-270.6565. E-mail: marise@ioc.fiocruz.br

Received 15 December 1999

Accepted 2 May 2000 tential for dissemination in the wards, high levels of antibiotic resistance, associated with high rates of morbidity and mortality (Soares et al. 1997, Tambic et al. 1997, Conterno et al. 1998).

The prevalence of MRSA in Brazil is considered elevated, specially in large hospitals (Branchini et al. 1993, Sader et al. 1994a), and in despite of the wide distribution, there are some hospitals that never had MRSA outbreak (Teixeira et al. 1996).

Risk factors associated with aquisition of MRSA include premature birth, low weight, respiratory problems, immunodeficiency, prophilatic antimicrobial use, long time of hospitalization, infections of the respiratory tract, and invasives diagnostic and cirurgical procedures (Haley et al. 1995, Pujol et al. 1996, Corbella et al. 1997, Villari et al. 1998). Transmission of strains occurs generally through contact of health care workers with colonized or infected patient before their isolation and proper management (Corbella et al. 1997).

Epidemiological transmission studies of MRSA have been traditionally performed by phenotypic characterization (Bannerman et al. 1995, Na'Was et al.1998), therefore, the increasing of the molecu- 
lar epidemiology studies revolutioned our understanding of diseases transmission and allowed to recognize and investigate outbreaks in ways never before possible (Ostroff 1999). The identification of several new clones and distribution of endemics and epidemics strains became feasable through the use of molecular tools as pulsed field gel electrophoresis (PFGE) and restriction fragment length polymorphism (RFLP) of chromossomal DNA associated with hybridization techniques (Kreiswirth et al. 1993, Teixeira et al. 1995, Tambic et al. 1997).

In this study we describe the bacteriological and epidemiological characteristics of MRSA, isolated from anterior nares and blood of newborns hospitalized in a public maternity hospital in the city of Rio de Janeiro, Brazil, and their genetic analysis by PFGE as an epidemiological marker.

\section{MATERIALS AND METHODS}

Patients - The Hospital Maternidade Alexander Fleming II is a maternity-childhood hospital in the city of Rio de Janeiro, Brazil, providing assistance and perinatal care including a neonatology intermediate care unity (NIU) with 40 beds and a neonatology intensive care unity (NICU) with 15 beds.

After the detection of a positive blood culture for MRSA from a hospitalized newborn in the NICU in April 1998 (index case), a prospective study was realized for detection of MRSA in anterior nares of hospitalized newborns and health care workers in the NICU and NIU. A total of 332 nasal swabs were taken from anterior nares in following goups: newborns group 1 (NBG 1), samples from 90 newborns collected at the period between 04/13 and 04/16/98; NBG 2, 82 samples from newborns with MRSA colonization belonged to NBG 1 submitted to descolonization treatment by nasal aplication of $2 \%$ mupirocin ointment and bathing in $4 \%$ chlorexidine solution; NBG 3, samples from 56 newborns hospitalized, collected at the period between 04/27 and 05/04/98, after the adoption of control procedures and treatment of the colonized newborns group (NBG 1); NBG 4 , samples from 104 neonatology health care workers collected in the same period of the newborns included in NBG 1. In adition, with the objective to control the MRSA transmission, all staff adopted contact isolation precautions such as handwashing, gloving and gown use for the management of the infected newborns.

All MRSA (12 strains) isolated from blood cultures of hospitalized newborns with hospital infection, during the period from April 1997 to April 1999 were genetically analyzed and compared to those isolated from anterior nares secretions. As we detected a interval of 8 months (08/14/97-04/ 01/98) without positive blood culture for MRSA, we considered the strain $5 \mathrm{BC}$ isolated in 04/01/ 98 , as the index case to study the patients and staff carriers.

Bacterial strains and susceptibility testing Culture for $S$. aureus using nasal secretion and blood as well as identification of the organism were performed according to Kloos and Bannerman (1995). The MRSA characterization was made by antimicrobial susceptibility tests performed with disk diffusion method according to NCCLS (National Committee for Clinical Laboratory Standards 1997). The following concentrations of the antimicrobials drugs were used: penicillin $(10 \mathrm{U})$, ampicillin $(10 \mathrm{mcg})$, cephalotin $(30 \mathrm{mcg})$, oxacillin (1 mcg), amikacin (30 mcg), erythromycin (15 $\mathrm{mcg})$ and vancomycin $(30 \mathrm{mcg})$. The reference strain S. aureus (ATCC 25923) was used as a quality control.

PFGE - The chromossomal DNA restriction analysis of 43 MRSA isolated from anterior nares and 12 from blood were performed by PFGE. Therefore, strains were submitted to chromossomal DNA extraction and processing according to the procedure described by Sader et al. (1994b). Nucleic acids present in the agarose plugs were digested with $10 \mathrm{U} \mathrm{SmaI}$ at $30^{\circ} \mathrm{C}$ during $20 \mathrm{~h}$ and electrophoresis was performed at $6 \mathrm{~V} / \mathrm{cm}$ during 23 $\mathrm{h}$ in $0.5 \mathrm{X} \mathrm{TBE}$ at $13^{\circ} \mathrm{C}$ in $1 \%$ agarose gel using a ramping switch time of 1-50 sec. All agarose gels were made for twice to verify the reproducebility of the tests.

Band patterns were analized using Gelcompar 4.1 (Applied Maths, Belgium), without using internal markers. The similarities between fingerprints were determined by construction of a similarity matrix using the Dice coefficient with $1.5 \%$ position tolerance, what generated a dendrogram using the UPGMA clustering algorithm.

Definition of clonal structure of MRSA isolates was according to Tenover et al. (1995): PFGE patterns with more than $90 \%$ similarity under the stringency conditions defined in this study were considered as the same clone.

\section{RESULTS}

The frequency of MRSA isolated from nasal swabs in the four groups analyzed was higher in NBG 1 (43 positive cultures; 47.8\%). In NBG 2, two positive cultures were obtained from two newborns carriers (NBG 1) submitted to descolonization treatment. No positive cultures were obtained from NBG 3 and NBG 4. Upon 43 newborns with positive nasal swabs for MRSA, $32(74.4 \%)$ were assymptomatic, 6 (14\%) showed a clinical picture compatible with $S$. aureus infection (pneumonia, sepsis or meningitis), while 5 more (11.6\%) died with generalized infection caused by MRSA. 
All MRSA strains were resistant to all antimicrobials utilized in the susceptibility test, with exception to vancomycin.

Upon genetic analysis of MRSA isolates from anterior nares, 8 different PFGE patterns were observed among the 43 strains analyzed (Fig. 1-A) and in the construction of a dendrogram, these patterns were divided into two main genetic clusters (Fig. 2). The first cluster, designed cluster I, had $86 \%$ percent of the strains isolated from nasal swabs and consisted of pattern A (26 strains); from four more probably and closely related patterns were observed in 11 strains (A1: 5 strains; A2: 2 strains; A3: 1 strain and A4: 3 strains). The second, designed cluster II, consisted of 3 different patterns observed in 6 more strains (B: 2 strains;
C: 3 strains and D: 1 strain).

We detected 8 different profiles in the PFGE analysis of the 12 MRSA strains isolated from blood, along two years (Fig.1-B, C). A dendrogram constructed from all profiles (Fig. 3) revealed that $9(75 \%)$ strains were genetic related to nasal secretion isolates, with the following distribution: $50 \%$ of MRSA isolates $(2 \mathrm{BC}, 6 \mathrm{BC}, 8 \mathrm{BC}, 9 \mathrm{BC}$, $10 \mathrm{BC}$ and $12 \mathrm{BC}$ ) had 90 to $96 \%$ of similarity to clone $\mathrm{A} 1 ; 25 \%$ (3BC, 4BC, and 5BC) had 94 to $100 \%$ of similarity to the clone $\mathrm{A} 4$ and the patterns $1 \mathrm{BC}, 7 \mathrm{BC}$ and $11 \mathrm{BC}$ apparently form a distinct genetic group in this analysis.

The distribution of blood culture MRSA chromossomal profiles according to isolation date and type of anterior nares clone (Table) showed

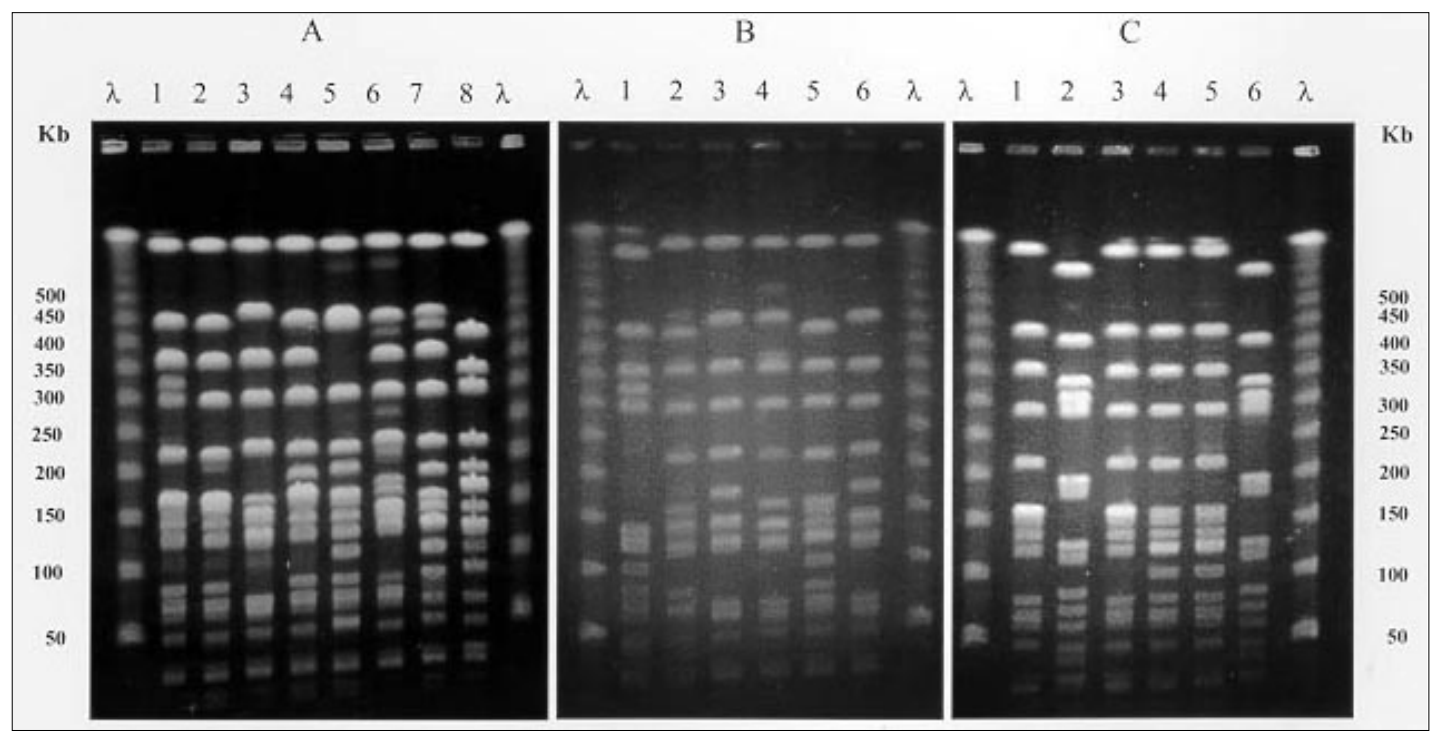

Fig. 1: $\lambda$ : lambda ladder pulsed field gel electrophoresis marker (50-1000 Kb); A (lanes 1-8): chromossomal profiles detected in 43 strains of methicilin resistant Staphylococcus aureus from anterior nares of newborns - 1: A (26 strains); 2: A1 (5 strains); 3 : A4 (3 strains); 4: A2 (2 strains); 5: B (2 strains); 6: A3 (1 strain); 7: C (3 strains); and 8: D (1 strain); B and C: chromossomal profiles detected in 12 strains of MRSA isolated from blood culture (BC) during two years; 1-6 (B): 1BC, 2BC, 3BC, 4BC, $12 \mathrm{BC}$, and $5 \mathrm{BC}$, respectively; 1-6 (C): 6BC, 7BC, 8BC, 9BC, 10BC and 11BC, respectively

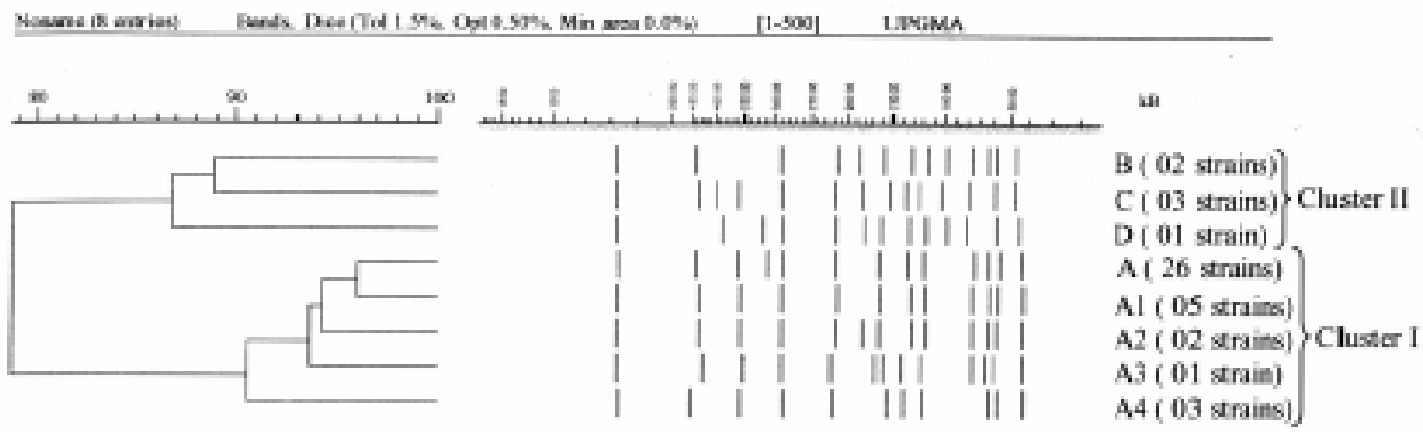

Fig. 2: dendrogram illustrating the similarity among chromossomal profiles detected by pulsed field gel electrophoresis in 43 strains isolated from anterior nares of newborns (A - A4, B, C and D). 


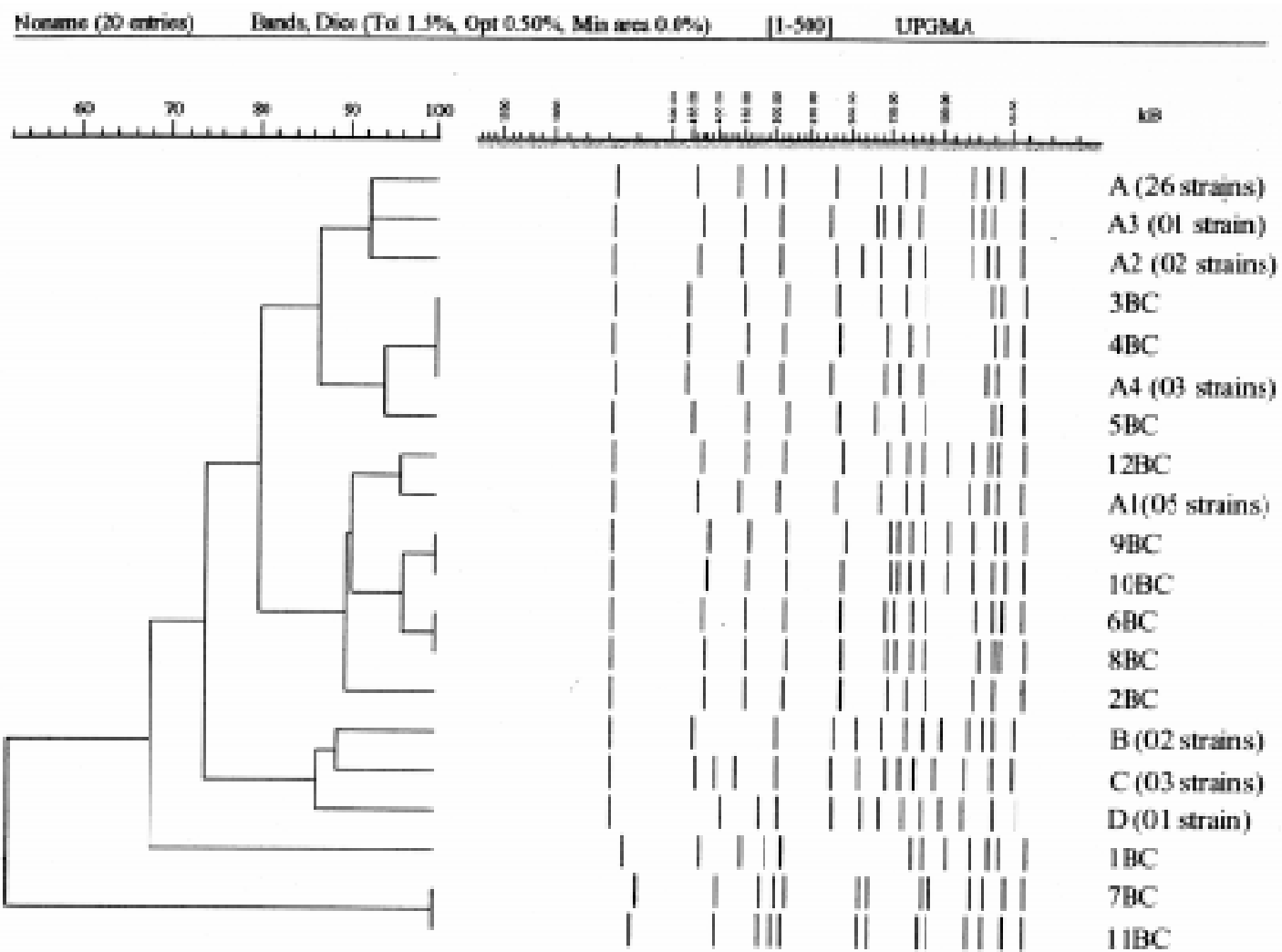

Fig. 3: a comparative dendrogram among 43 strains isolated from anterior nares (A - A4, B, C and D) and 12 strains from blood culture (BC) of newborns (1BC - $12 \mathrm{BC}$ )

that the clone A4 had similar PFGE profiles in the strain that started the epidemiological study (5BC) and the strains $3 \mathrm{BC}$ and $4 \mathrm{BC}$, both isolated from blood culture 8 months before. The clone A1, also was observed similar PFGE profile in one strain (12BC) isolated from blood culture one year later the investigation of nasal carriers.

\section{DISCUSSION}

Infections with MRSA increase significantly the cost of hospitalization, mortality and morbidity rates of hospitalized patients, especially newborns (Jarvis 1987, Wenzel 1994, Smith \& Doebbeling 1996). Detection of nasal MRSA carriers in hospitalized patients and in hospital staff by a variety of procedures has been associated with decreasing levels of infections and prevention of the transmission of these microrganisms (Blumberg \& Klugman 1994).

Isolation of MRSA in nasal secretion of almost half of the hospitalized newborns from NBG 1 investigated in this study revealed the existence of significant colonization of the organism in that

\section{TABLE}

Distribution of blood culture methicillin resistant Staphylococcus aureus DNA profiles according to isolation date and type of anterior nares clone

\begin{tabular}{|c|c|c|}
\hline $\begin{array}{l}\text { Blood culture methicillin } \\
\text { resistant } S \text {. aureus } \\
\text { chromossomal } \\
\text { DNA profiles }\end{array}$ & $\begin{array}{c}\text { Isolation } \\
\text { date }\end{array}$ & $\begin{array}{c}\text { Anterior } \\
\text { nares clone }\end{array}$ \\
\hline $1 \mathrm{BC}$ & $04 / 21 / 97$ & DP \\
\hline $2 \mathrm{BC}$ & 06/30/97 & A1 \\
\hline $3 \mathrm{BC}$ & 08/0797 & A4 \\
\hline $4 \mathrm{BC}$ & 08/14/97 & A4 \\
\hline $5 \mathrm{BC}^{a}$ & 04/01/98 & A4 \\
\hline $6 \mathrm{BC}$ & 07/07/98 & A1 \\
\hline $7 \mathrm{BC}$ & $12 / 09 / 98$ & DP \\
\hline $8 \mathrm{BC}$ & $12 / 09 / 98$ & A1 \\
\hline 9BC & $12 / 23 / 98$ & A1 \\
\hline $10 \mathrm{BC}$ & $12 / 24 / 98$ & A1 \\
\hline $11 \mathrm{BC}$ & $03 / 31 / 99$ & DP \\
\hline $12 \mathrm{BC}$ & $04 / 16 / 99$ & A 1 \\
\hline
\end{tabular}

$a$ : index case that motivate the study of colonization; DP: different pattern 
population. The treatment with $2 \%$ mupirocin ointment, the drug of choice for treatment of nasal colonization with MRSA, associated with bathing in a $4 \%$ solution of chlorexidine were efficient to eliminate the MRSA from NBG 1. After this treatment, the control cultures for descolonization were negative (NBG 2). These data are in agreement with other reports on the efficacy of prevention of transmission of the pathogen by these measures (Blumberg \& Klugman 1994, Chatfield et al. 1994, Coello et al. 1994, Teixeira et al. 1996, Tambic et al. 1997). Therefore, one month after the drug administration two patients revealed MRSA in anterior nares. Because the control cultures were negative, probably these newborns were reinfected by MRSA. Unfortunately, we did not have these two MRSA strains to include into epidemiological and molecular analysis.

The fact that $74.4 \%$ of the individuals with colonized anterior nares studied were assymptomatic demonstrates the need for large scale monitoration of nasal carriers of MRSA by culture. Earlier studies have shown the participation of clinical staff in the spreading of MRSA in hospitals through manipulation of carriers without the adoption of precaution measures, and the importance of nasal carriage for development of disease (Tambic et al. 1997, Villari et al. 1998). In this study however, none of the members of the hospital staff was found to be a carrier of MRSA and probably transmitted the microrganism by hands.

Because of its reproducibility and discriminatory capacity, the separation of cleaved genomic DNA by PFGE has been shown to be an excellent typing technique for MRSA in comparison with more classical or other molecular typing methods (Bannerman et al. 1995, Haley et al. 1995, Na'Was et al. 1998).

In this study, $60 \%$ of the isolates from nasal secretion (26 strains) had an identical PFGE profile, suggesting that transmission of a single strain occurred extensively within the hospital unit. Eightysix percent of the nasal strains belonged to a cluster I of at least $90 \%$ similarity meaning that most of the strains isolated during a 4-day period were highly related. Also, $75 \%$ of the MRSA strains isolated from blood during a period of two years had a similarity of more than $90 \%$ to patterns of strains isolated from nasal secretion; this observation suggests that strains are endemic in this hospital unit and these results are in agreement with Haley et al. (1995), who described the persistance of a MRSA strain in the neonatal intensive care unit in a hospital in Texas during three years, even after implementation of control measures.

Our observations of similar PFGE patterns in strains isolated from the nose and blood, specially in newborns who developed MRSA pathologies agree with earlier suggestions that the respiratory tract is the primary port of entry for colonization and can lead to pneumonia, septicemia and death (Pujol et al. 1994, 1996, Corbella et al. 1997, Cordero et al. 1997).

In conclusion, our data demonstrated the importance of screening the newborns for the presence of MRSA in Brazilian hospitals and the usefulness of genetic typing of these pathogen during epidemiologic studies on a small and large scale basis. This should lead to a better knowledge on the significancy and spreading of MRSA in the hospitals.

\section{REFERENCES}

Bannerman TL, Hancock GA, Tenover FC, Miller JM 1995. Pulsed-field gel electrophoresis as a replacement for bacteriophage typing of Staphylococcus aureus. J Clin Microbiol 33: 551-555.

Blumberg LH, Klugman KP 1994. Control of methicillin-resistant Staphylococcus aureus bacteraemia in high-risk areas. Eur J Clin Microbiol Infect Dis 13: $82-85$

Boyce JM, Jackson MM, Pugliese G, Batt MD, Fleming D, Gerner J, Hartstein AI, Kaufmann CA, Simmons M, Wenstein R, Willians CO 1994. Methicillin-resistant Staphylococcus aureus (MRSA): a brief for acute care hospitals and nursing facilities. Infect Control Hosp Epidemiol 15: 105-115.

Branchini MLM, Moethland VH, Tresoldi AT, Nowakousky AV, Dias MB, Pfaller MA 1993. Application of genomic DNA subtyping by pulsed field gel electrophoresis and restriction enzyme analysis of plasmid DNA to characterize methicillin-resistant Staphylococcus aureus from two nosocomial outbreaks. Diagn Microbiol Infect Dis 17: 275-281.

Chatfield CA, O'Neill WA, Cooke RPD, McGhee KJ, Issack M, Rahman M, Noble WC 1994. Mupirocinresistant Staphylococcus aureus in a Specialist School population. J Hosp Infect 26: 273-278.

Coello R, Jiménez J, Garcia M, Arroyo P, Minguez D, Fernández C, Cruzet F, Gaspar C 1994. Prospective study of infection, colonization and carriage of methicillin-resistant Staphylococcus aureus in an outbreak affecting 990 patients. Eur J Clin Microbiol Infect Dis 13: 74-81.

Conterno LO, Wey SB, Castelo A 1998. Risk factors, for mortality in Staphylococcus aureus bacteremia. Infect Control Hosp Epidemiol 19: 32-37.

Corbella X, Domínguez MA, Pujol M, Ayats J, Sendra M, Pallares R, Ariza J, Gudiol F 1997. Staphylococcus aureus nasal carriage as a marker for subsequent staphylococcal infections in intensive care unit patients. Eur J Clin Microbiol Infect Dis 16: 351-357.

Cordero L, Ayers LW, Davis K 1997. Neonatal airway colonization with Gram-negative bacilli: association with severity of bronchopulmonary dysplasia. Ped Infect Dis J 16: 18-23.

Haley RW, Hightower AW, Khabbaz RF, Thornsberry C, Martone WJ, Allen JR, Hughes JM 1982. The 
emergence of methicillin-resistant Staphylococcus aureus in the United States hospitals. Ann Intern Med 97: 297-308.

Haley RW, Cushion NB, Tenover FC, Bannerman TL, Dryer D, Ross J, Sánchez PJ, Siegel JD 1995. Erradication of endemic methicillin-resistant Staphylococcus aureus infections from a neonatal intensive care unit. J Infect Dis 171: 614-624.

Jarvis WR 1987. Epidemiology of nosocomial infections in pediatric patients. Ped Infect Dis J 6: 344351.

Kloos WE, Bannerman TL 1995. Staphylococcus and Micrococcus. In PR Murray, EJ Baron, MA Pfaller, FC Tenover, RH Yolken (eds), Manual of Clinical Microbiology, ASM press, Washington DC, p. 282298.

Kreiswirth B, Kornblum J, Arbeit RD, Eisner W, Maslow JN, McGeer A, Low DE, Novick RP 1993. Evidence for a clonal origin of methicillin resistance in Staphylococcus aureus. Science 259: 227-230.

NCCLS - National Committee for Clinical Laboratory Standards 1997. Methods for dilution antimicrobial tests for bacteria that grow aerobically. Approved standard M7-A4. NCCLS, Wayne, PA.

Na'Was T, Hawwari A, Hendrix E, Hebden J, Eldeman R, Martin M, Campbel W, Naso R, Schwalbe R, Fattom AI 1998. Phenotypic and genotypic characterization of nosocomial Staphylococcus aureus isolated from trauma patients. J Clin Microbiol 36: 414420.

Ostroff SM 1999. Emerging infectious diseases 19971998: the role of molecular epidemiology. Mem Inst Oswaldo Cruz 94: 1-3.

Pujol M, Peña C, Pallares R, Ayats J, Ariza J, Gudiol F 1994. Risk factor for nosocomial bacteremia due to methicillin-resistant Staphylococcus aureus. Eur J Clin Microbiol Infect Dis 13: 96-102.

Pujol M, Peña C, Pallares R, Ariza J, Ayats J, Dominguez MA, Gudiol F 1996. Nosocomial Staphylococcus aureus bacteremia among nasal carriers of methicillin-resistant and methicillin-susceptible strains. Am J Med 100: 509-516.

Sader HS, Pfaller MA, Jones RN 1994a. Prevalence of important pathogens and the antimicrobial activity of parenteral drugs at numerous medical centers in the United States. II. Study of the intra-and inter- laboratory dissemination of extended spectrum $\beta$ lactamase producing enterobacteriaceae. Diagn Microbiol Infect Dis 20: 203-208.

Sader HS, Pignatari AC, Hollis R, Jones RN 1994b. Evaluation of interhospitalar spread of methicillinresistant Staphylococcus aureus in São Paulo, Brazil, using pulsed field gel electrophoresis of chromossomal DNA. Inf Control Hosp Epidemiol 15: $320-323$.

Smith SD, Doebbeling BN 1996. Costs of nosocomial infections. Cur Opin Infect Dis 9: 286-290.

Soares MJS, Tokumaru-Miyazaki NH, Noleto ALS, Figueiredo AMS 1997. Enterotoxin production by Staphylococcus aureus clones and detection of Brazilian epidemic MRSA clone (III::B:A) among isolates from food handlers. J Med Microbiol 46: 214 221.

Tambic A, Power EGM, Talsania H, Anthony RM, French GL 1997. Analysis of an outbreak of nonphage-typeable methicillin-resistant Staphylococcus aureus by using a randomly amplified polymorphic DNA assay. J Clin Microbiol 35: 3092-3097.

Teixeira LA, Resende CA, Ormonde LR, Rosenbaum R, Figueiredo AMS, de Lencastre H, Tomasz A 1995. Geographic spread of epidemic multiresistant Staphylococcus aureus clone in Brazil. J Clin Microbiol 33: 2400-2404.

Teixeira LA, Lourenço MCS, Figueiredo, AMS 1996. Emergence of a methicillin-resistant Staphylococcus aureus clone related to the Brazilian epidemic clone III::B:A causing invasive disease among AIDS patients in a Brazilian hospital. Microb Drug Resist 2: 393-399.

Tenover FC, Airbeit RD, Goering RV, Mickelsen PA, Murray BE, Persing DH, Swaminathan B 1995. Interpreting chromossomal DNA restriction patterns produced by pulsed-field gel electrophoresis: criteria for bacterial strain typing. J Clin Microbiol 33: 2233-2239.

Villari P, Lacuzio L, Torre I, Scarcella A 1998. Molecular epidemiology as an effective tool in the surveillance of infections in the neonatal intensive care unit. J Infect 37: 274-281.

Wenzel RP 1994. Epidemiology of hospital-acquired infection. In A Ballows, Manual of Clinical Microbiology, ASM press, Washington, DC, p. 147-150. 